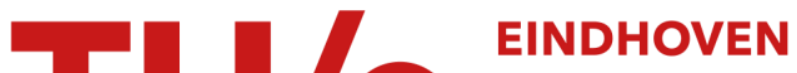 UNIVERSITY OF TECHNOLOGY
}

\section{Tracebook : a dynamic checklist support system}

\section{Citation for published version (APA):}

Nan, S., Van Gorp, P. M. E., Korsten, H., Vdovják, R., \& Kaymak, U. (2014). Tracebook : a dynamic checklist support system. (BETA publicatie : working papers; Vol. 450). Technische Universiteit Eindhoven.

\section{Document status and date:}

Published: 01/01/2014

\section{Document Version:}

Publisher's PDF, also known as Version of Record (includes final page, issue and volume numbers)

\section{Please check the document version of this publication:}

- A submitted manuscript is the version of the article upon submission and before peer-review. There can be important differences between the submitted version and the official published version of record. People interested in the research are advised to contact the author for the final version of the publication, or visit the DOI to the publisher's website.

- The final author version and the galley proof are versions of the publication after peer review.

- The final published version features the final layout of the paper including the volume, issue and page numbers.

Link to publication

\section{General rights}

Copyright and moral rights for the publications made accessible in the public portal are retained by the authors and/or other copyright owners and it is a condition of accessing publications that users recognise and abide by the legal requirements associated with these rights.

- Users may download and print one copy of any publication from the public portal for the purpose of private study or research.

- You may not further distribute the material or use it for any profit-making activity or commercial gain

- You may freely distribute the URL identifying the publication in the public portal.

If the publication is distributed under the terms of Article $25 \mathrm{fa}$ of the Dutch Copyright Act, indicated by the "Taverne" license above, please follow below link for the End User Agreement:

www.tue.nl/taverne

\section{Take down policy}

If you believe that this document breaches copyright please contact us at:

openaccess@tue.nl

providing details and we will investigate your claim. 


\section{Beta}

Research School for Operations

Management and Logistics

Tracebook: A Dynamic Checklist Support System

Shan Nan, Pieter Van Gorp, Hendrikus H.M. Korsten, Richard Vdovjak, Uzay Kaymak

Beta Working Paper series 450

\begin{tabular}{|rl|}
\hline BETA publicatie & WP 450 (working \\
& paper) \\
ISBN & \\
ISSN & \\
NUR & 982 \\
Eindhoven & March 2014 \\
\hline
\end{tabular}




\title{
Tracebook: A Dynamic Checklist Support System
}

\author{
Shan Nan*§, Pieter Van Gorp*, Hendrikus H.M. Korsten ${ }^{\dagger *}$, Richard Vdovjak ${ }^{\ddagger}$, Uzay Kaymak*, \\ Xudong $\mathrm{Lu}^{\S}$ and Huilong Duan ${ }^{\S}$ \\ ${ }^{*}$ School of Industrial Engineering, Eindhoven University of Technology, Eindhoven, The Netherlands \\ \{s.nan,p.v.gorp,u.kaymak\}@tue.nl \\ $\dagger$ Department of Aneasthiaology and Intensive-Care, Catharina Ziekenhuis Eindhoven, The Netherlands \\ erik.korsten@catharinaziekenhuis.nl \\ $\ddagger$ Philips Research, Eindhoven, The Netherlands \\ richard.vdovjak@philips.com \\ $\S$ Department of Biomedical Engineering, Zhejiang University, Hangzhou, P.R. China \\ $\{$ lvxd,duanhl\}@zju.edu.cn
}

\begin{abstract}
It has recently been demonstrated that checklists can enable significant improvements to patient safety. However, their clinical acceptance is significantly lower than expected. This is due to the lack of good support systems. Specifically, support systems are too static: this holds for paper-based support as well as for electronic systems that digitize paper-based support naively. Both approaches are independent from clinical process and clinical context. In this paper, we propose a process-oriented and context-aware dynamic checklist support system: Tracebook. This system supports the execution of complex clinical processes and rules involving data from Electronic Medical Record systems. Workflow activities and forms are specific to individual patients based on clinical rules and they are dispatched to the right user automatically based on a process model. Besides describing the Tracebook functionality in general, this paper demonstrates the support system specifically on an example application that we are preparing for a controlled clinical evaluation. At last we discuss the difference between Tracebook and other support systems which also rely on a checklist format.
\end{abstract}

\section{INTRODUCTION}

Checklists, sometimes referred to as "safety checklists" or "medical checklists", have in recent years gained support as vehicles for disseminating evidence-based best practices in clinical medicine, with the aim of improving patient safety [1], [2]. In clinical practice, they are completed by a responsive team in a well-defined process with the aim of increasing patient safety. Usually, team members verbally confirm and discuss all the tasks listed on checklists [3]. Sometimes checklists are handed to physicians and support staff working on support procedures [4].

Although two independent studies have reported how surgical safety checklist enabled significant reduction in mortality and morbidity [1], [2], practitioners are still reluctant to adopt these checklist in their daily practice [3]-[8]. The existing support systems are known to have the following limitations which cause adoption barrier: the lack of reminder mechanisms and the excessive length of checklists [4].

In other clinical knowledge related applications, e.g., clinical practice guideline, people have faced similar problems [9]. A number of clinical decision support systems (CDSSs) have been developed to solve the problems [10]. These systems present the best practice knowledge to users dynamically according to specific patient data by sending alerts. However, studies has found that these alerts did not apply to the patient due to alert fatigue. The reason is that these alerts are isolated from the clinical workflow and context [11].

In this paper, we apply the experiences of CDSSs and propose Tracebook, a dynamic checklist support system aiming to support the implementation of checklists in a processoriented, context-aware way. Tracebook works as an assistant to dispatch checklists to the right person according to clinical workflow and filter the content of checklists based on clinical rules. Moreover, Tracebook bridges participants who work in different phases and have little communication by presenting history checklists in a comprehensive process model. Additionally, by the name Tracebook, we stress the idea of teamwork. Tracebook intends to make clinical processes more traceable and accountable (e.g., by tracking and showing who was responsible for already completed activities). Also, similar to the non-medical social platforms (e.g., Facebook), Tracebook can make a (care) organization more open to its clients (as well as to colleagues from another organizational unit) so that they can know each other, by means of picture logs.

The remainder of this paper is structured as follows: Section II reviews current checklist support systems' functions and adoption/implementation barriers. Section III describes the features of a dynamic checklist support system and walks the reader through these features with an example. Section IV describes two other digital checklist support systems and discusses the major differences. Section V discusses the difference between dynamic checklist support systems, computerized clinical pathway systems and computerized provider order entry systems. Finally in section VI, we give a conclusion to this paper.

\section{BACKGROUND}

Clinical checklists are becoming increasingly popular in recent years for patient safety in both routine and emergency situations. Among these checklists, three of them are well studied and tested, which are the World Health Organization Surgical Safety Checklist (WHO SSC) [1], the SURgical PAtient Safety System (SURPASS) [2] and the Surgical-Crisis Checklist [12]. They have shown their great power in several well defined clinical trials [1], [2], [12]. Paper-based checklist 
support systems and static digital checklist support systems have been developed for the implementation. However, it has been reported that practitioners are reluctant to use these checklists and their variations due to the insufficiencies of these support systems [4], [5]. In the following subsection, we make a brief review of these checklist support systems' functionalities, achievements and limitations. Then, we discuss the reasons of these limitations.

\section{A. Functionalities of checklist support systems}

In 2007, the World Health Organization (WHO) launched the Safe Surgery Saves Lives Initiative, aiming at improving surgical safety by defining a core set of safety standards. The checklist mechanism was selected as the appropriate form to represent these standards because of its success in the aviation industry. This resulted in the WHO SCC, which has in the meanwhile been tested in a prospective pilot study in eight hospitals located in both developed and developing countries.

WHO SSC has three stages, the stage before induction of anesthesia, the stage before skin incision and the stage before the patient leaves the operating room (OR). In each stage, there is a collection of predefined patient safety related checks (e.g., is this the correct patient, the correct operation site/side, etc.). A team including an anesthesiologist, a surgeon and a nurse is required to preform those checks.

Paper-based systems are available to support the implementation of WHO SSC and its variations. They usually consist of one piece of paper with three blocks. In each block, checkable items that belong to one stage are listed. In each stage, a nurse, an anesthesiologist and a surgeon should stand together to confirm verbally whether the listed tasks have been performed and to document the checked results. The surgical process can only proceed after every item has been checked.

SURPASS was initially developed as early as 2004 in the Academic Medical Center (AMC) in Amsterdam, The Netherlands. It aims to improve surgical patient safety by providing a frame for the surgical pathway and promoting interdisciplinary communication.

Different from WHO SSC which is only used in the OR by a nurse, an anesthesiologist and a surgeon, SURPASS extends the use of the checklist to the ward, the OR, the recovery unit and the intensive care unit (ICU), for ward doctors, nurses, surgeons, anesthesiologists, intensivists and operating assistants. SURPASS spans a comprehensive peri-operative process including pre-operative activities on the ward, a timeout in the OR, activities in the recovery unit or ICU, postoperative ward activities and discharge related activities for a multidisciplinary team.

A paper-based support system for SURPASS was firstly introduced in 2008. 18 pages of checkable items are organized per process step. Some of them are optional based on whether or not the patient will receive local anesthesia. Some items are optional based on specific patient conditions. There are also areas to make notes or remarks related to the checks.

To improve the usage of the checklist and streamline the checklist process, in 2011, AMC rolled out SURPASS Digital, a web-based checklist support system integrated into the AMC's hospital information systems. SURPASS Digital provides static web pages of checkable items. The 18 pages of checklist are presented in a sequential order in the system to illustrate the peri-operative process. Users can review history checks in the system [13].

The purpose of the above two checklist support systems is to give standardized care to patients in routine situations. However, emergencies (e.g., cardiac arrest and massive hemorrhage) happen in critical clinical settings. The Surgical Crisis Checklist has been developed to improve adherence to evidence-based best practices during these emergencies [12]. It has been evaluated in a simulation-based trial.

The Surgical Crisis Checklist is a complementary to the WHO SSC as it provides a step-by-step guidance to rare but serious scenarios which are not included in the WHO SSC. The OR staff can pick up these checklists when certain kinds of emergencies happen.

A paper-based support system is available for the Surgical Crisis Checklist. The system relies on color coding and numbering for organizing the checkable items of 12 anticipated emergency situations. When a crisis happens, the OR staff can find the correct checklist more conveniently than without this organization technique. The checklists essentially have turned evidence-based best practices into actionable steps for dealing with critical scenarios. People are encouraged to confirm and discuss each step verbally. While WHO SSC and SURPASS require signatures of the participants, this is not the case for the Surgical Crisis Checklist.

To summarize, the functionalities of these checklist support systems are compared in TABLE I.

\section{B. Achievements and Insufficiencies}

WHO SSC reduced the overall mortality rate from $1.5 \%$ to $0.8 \%$ and the complication rate decreased from $11 \%$ to $7 \%$. The success encouraged WHO to release this checklist globally. More than 1800 hospitals had already used it routinely in 2009 [1].

Though it is wide-spread, the adherence to WHO SSC is reported low. Based on different statistical methods, the completion and compliance of WHO SSC are reported differently. A multi-center study [5] indicates that the completion rate and compliance rate are $61 \%$ and $90.2 \%$ respectively. Another single-site study [8] shows that the completion rate is $85 \%$ and the compliance rate is $69 \%$. Both of these studies expected a $100 \%$ completion and compliance. Barriers are identified in these studies, which are redundancy in the checkable items, poor communication, time consumption, inappropriate timing, identification of the role and responsibility of staff as well as users' attitude [5].

A prospective evaluation result shows that SURPASS reduced the mortality rate from $1.5 \%$ to $0.8 \%$ and the complication rate from $27.3 \%$ to $16.7 \%$ [2]. This checklist is routinely used in AMC and 5 other hospitals in the Netherlands.

The completion rate of SURPASS is less than expected. $65 \%$ of the surgeons completed checklist almost always, and only $35 \%$ of the anesthesiologists did so. Surgical staff was interviewed to find out the reasons. The most frequent reasons were "forgotten" with 66\%, "logistics" with $45 \%$, "lack of 
TABLE I: Functionalities and acceptance of checklist support systems

\begin{tabular}{|c|c|c|c|}
\hline Checklist & Support System & Functions & Barriers \\
\hline WHO SSC & Paper-based system & $\begin{array}{l}\text { Essential items confirmation } \\
\text { Decisions recording }\end{array}$ & $\begin{array}{l}\text { Duplication with existing checks } \\
\text { Poor communication } \\
\text { Time consuming } \\
\text { Inappropriate timing } \\
\text { Identification of the role and responsibility of staff } \\
\text { Users' attitude }\end{array}$ \\
\hline SURPASS & $\begin{array}{l}\text { Paper-based system from } 2008 \text { to } 2011 \\
\text { static digitalized system after } 2011\end{array}$ & $\begin{array}{l}\text { Explicit process map } \\
\text { Role based task assignment } \\
\text { Process logging } \\
\text { Essential items confirmation } \\
\text { Decisions recording } \\
\text { Remarks on problems }\end{array}$ & $\begin{array}{l}\text { Forget now and then } \\
\text { Logistics } \\
\text { Lack of time } \\
\text { Motivation } \\
\text { Other }\end{array}$ \\
\hline CRISIS & Paper-based system & $\begin{array}{l}\text { Emergency in process } \\
\text { Step-by-step guidance }\end{array}$ & N/A (Not implemented) \\
\hline
\end{tabular}

time" with $34 \%$ as well as "motivation" and "others" with $11 \%$. Integration into hospital information system, providing electronic checklist and making checklist shorter were suggested to improve the compliance of SURPASS [4].

The Surgical Crisis Checklist has been evaluated in a simulation-based study. Non-adherence to critical procedures decreased from $23 \%$ to $6 \%$ [12]. Participants of the evaluation claim that they would like to use this checklist in their work. However, the implementation in real clinical situations has not been reported yet. A summary of the barriers reported in the literature is given in TABLE I.

\section{Static nature of existing checklist support systems}

Current checklist support systems are "too static" in two respects.

1. Checklist support systems are static in terms of the process. Here, the process refers to the collection of checklist-related activities and the order between them. Currently, checklist support systems have a poor division of responsibilities of the people involved. Thus, users may forget or feel unclear about their roles and fail to perform checks at the appropriate time.

2. Checklist support systems are static in terms of the context. Here, the context refers to the data related to the condition of the patient (e.g., diagnosis, co-morbidities, laboratory tests, prescription, demographic information, etc.). In current checklist support systems, items in the checklist are the same for every patient, regardless whether they may need significantly different concerns. Thus, checklists are excessively long. Based on the aforementioned studies on alert fatigue, it is clear that a lack of prioritization support can drain users' motivation.

As a result, solving the "static" problems is the key to developing a well-accepted checklist support system. Comparing with current checklist support systems, we characterized such a system as a dynamic checklist support system, which should be process-oriented and context-aware.

\section{TRACEBOOK: A DYNAMIC CHECKLIST PROTOTYPE}

In this section, we describe a dynamic checklist support system, Tracebook, which supports all the checklist functionalities stated in the above section and provides dynamic features which are process-oriented and context-aware. An additional benefit of Tracebook is that it can make clinical processes more transparent, traceable and accountable by tracking and showing the responsible persons of already completed activities. In this way, it forms a bridge amongst participants who work in different phases, time and places.

\section{A. Features}

Characterized as process-oriented, Tracebook has the following features.

Tracebook supports both predefined processes and adhoc processes. Both predefined processes like the process in SURPASS and ad-hoc processes like the process in the Surgical Crisis Checklist are supported. Moreover, these two kinds of processes can work simultaneously.

Tracebook supports complex flows. Complex flows which have events, conditional branches, gateways, timers, etc. can be executed in Tracebook. This feature guarantees that individual users can work on the same process concurrently. Also, it ensures that the system distributes checkable items at the most appropriate time.

Tracebook gives an overview of clinical processes. Tracebook logs each user's choices for a patient as well as the context when they made the decision. Users can inspect what the others have checked for a patient and why which decisions were taken by whom. This gives a transparent view to the process and can improve the accountability of the medical staff.

Tracebook is event driven. Event driven means that certain activities can be triggered by clinical events automatically. These events can be manual operations, messages from outside clinical systems, or timer events. It gives Tracebook the interoperability with clinical information systems so that the tasks can be executed at the right time.

Tracebook can assign checklists to both a group of users with the same role and a specific user automatically. Tracebook can distribute tasks to a certain group of user by their role or a particular user based on rules (e.g., a preoperative checklist is distributed to a group of surgeons. A surgeon picks up this pre-operative checklist. Then the postoperative checklist will be sent to this surgeon instead of all the surgeons).

Characterized as context-aware, Tracebook has the following features. 
Context-based task filtering and assignment. Tasks for a certain scenario can be filtered and assigned to the user according to patient data. It can perform automatic checks to reduce the workload, or perform double checks to increase the safety. It can also remove the irrelevant tasks in order to help the users to be more concentrated. Patient-based warnings or alerts can be presented as items in a checklist by this feature.

Context-based data and information supplementary. For each task, based on particular rules, patient data or additional information related to the task can be acquired by users at the time they need it. (i.e., via a contextualized pop-up over a checkable item). Thus they do not need to check patient information in different clinical information systems.

Triggering other tasks automatically. With the context and/or decisions users make, Tracebook can check whether preconditions of a task are met or successor actions should be started. Events and data in Tracebook can be sent to other information systems automatically as well.

Note and remark on each item. Tracebook allows a user to make a note and/or a remark on each item. These notes and remarks can be read by the other users. Highlights are provided in the process history view to help users in seeing at a glance all comments from human colleagues.

\section{B. Walk-through of an OR-ICU checklist}

We use an OR-ICU checklist, which is adopted from SURPASS and contains ad-hoc checkable items like Crisis Checklist, and an imaginary patient, John Doe, to walk through the features of Tracebook.

The OR-ICU checklist has three stages, pre-operative check, time-out in OR and admission to the ICU. When the operation is planned, the pre-operation checklist should be checked by a surgeon, a nurse and an anesthesiologist respectively in their offices. When the patient is sent to the $\mathrm{OR}$, an anesthesiologist, a surgeon and a nurse work together to perform a verbal confirmation. Further, when the patient is admitted to the ICU, an ICU nurse and a doctor need to check the admission to the ICU checklist. The whole process is illustrated in Fig. 1. Besides the scheduled checks, ad-hoc checklists for unscheduled events are also provided.

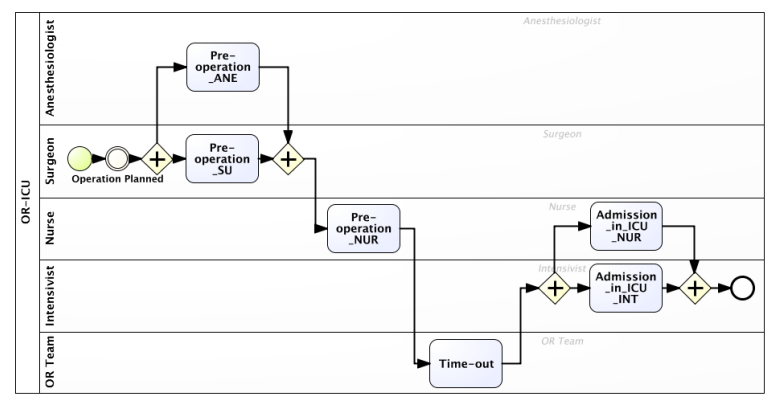

Fig. 1: OR-ICU checklist process.

Patient John Doe is planned for a coronary artery bypass graft $(\mathrm{CABG})$ surgery. He is on anticoagulation, which may lead to excessive bleeding during the surgery. So the international normalized ratio (INR) should be checked in this specific case. He has an impaired renal function, which should be known to the doctors while prescribing drugs. Due to alert fatigue, these two points are very likely to be overlooked in the EMR. He might carry vancomycin-resistant enteroccoccus (VRE) bacteria. And this bacteria might spread to the other sicker patients. In that case, he should be isolated by a standardized protocol.

With all the foreseeable and unforeseeable risks, the ORICU checklist is applied to John's care journey supported by Tracebook. When the operation is planned, the EMR system sends an event to Tracebook. The workflow engine inside of Tracebook catches this event and starts a new OR-ICU checklist process. Activities in the process are assigned to the predefined roles by the workflow engine. The users can see the checklist immediately (e.g., emails are sent to participants' mailboxes). Also, they can login to Tracebook later to find a list of checklists that they can check (Fig. 2).

Subject: $\quad$ Tracebook] New "Pre-operation_ANE" Checklist for Patient 1101
Dear Anesthesiologist, Email notification
You have a new "Pre-operation_ANE" checklist for patient 1101:
http://145.120.11.239/ChecklistSolution/ChecklistSheetFrame.ashx?
ChecklistID=1101SimpleSURPASS202413
Tracebook
Current checklists
Staff ID: ANEEKN
Role ID:Assigned
Please check Pre-operation_ANE for patient: 1101.
Role ID:ORTEAM
Role ID:ANE
Role ID:INT

Fig. 2: Picking up a checklist in the process.

When a user chooses a checklist, he or she will confirm the listed items and mark them. Instead of giving a long list that contains irrelevant items for the specific patient, in Tracebook, contextual clinical rules are used to filter existing items based on specific patient data in the EMR. Only patientspecific checks are displayed. Here for example (in Fig. 3, red font), two clinical rules " $I F$ Warfarin Prescribed=true $A N D$ INR $\geq 4.0$ THEN return 'Patient INR too high (INR value) noticed" and "IF Renal Insufficientcy=true THEN return 'Renal insufficiency noticed"' are predefined in Tracebook. The rule engine in Tracebook acquires patient data from the EMR and executes these rules. As a result, two more check items, "Patient INR too high (4.1) noticed" and "Renal insufficiency noticed" are provided by Tracebook. Another added value to the checklist provided by Tracebook is the quick access to patient data and multimedia resources. As illustrated in Fig. 3, when the user clicks on the underscored text, Tracebook will display an information pop-up to show the most recent data or lead to additional resources like clinical guidelines. A note or remark can be attached to each check. After checking and 
remarking, the checklist is submitted.
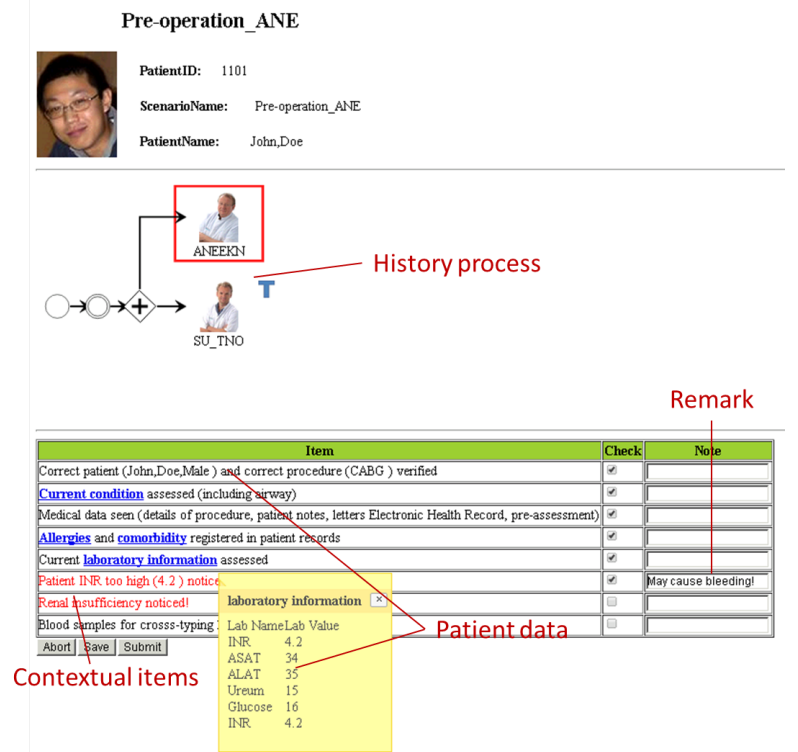

Fig. 3: Performing checks in a context-aware checklist.

When the operation is started, the medical team is assembled together in the OR to discuss the patient situation. The time-out checklist is assigned to the users who did the check in the previous stage by the workflow engine. After the operation, John is sent to the ICU. There, an intensivist and a nurse need to know his conditions, including the operation details. In Tracebook, there is a comprehensive view in Business Process Modeling and Notation (BPMN) format customized with participants' photos. Tracebook queries from the workflow engine that which tasks will be performed, which tasks should be performed at this moment and which tasks have been performed. Tasks that should be performed at this moment are highlighted with a red rectangular. Tasks that have been performed are marked with the performers' photos. Clicking on each photo, the current user can see what the others have checked and remarked (Fig. 4). Those patient data and additional resources are kept together with the history checklist. In this way, warnings and important remarks which are easily ignored in the EMR and the other information systems are kept together. Successor users can know from that why previous users made a particular decision. Another important feature is that the responsible person's contact information is placed together with their checks. When users have any doubt, they can directly call the one who made the check.

Unfortunately, John is infected with VRE. This is an unexpected situation that can not be planned. There is an "Adhoc checklist" page in Tracebook. Users can see the completed ad-hoc checklists which have been performed in previous stages for this patient. By typing keywords, users can find the VRE checklist very easily and perform their own checks (Fig. 5).

This prototype makes the whole process transparent and traceable. This guarantees a better team communication and promotes team building. Also, for each specific role involved

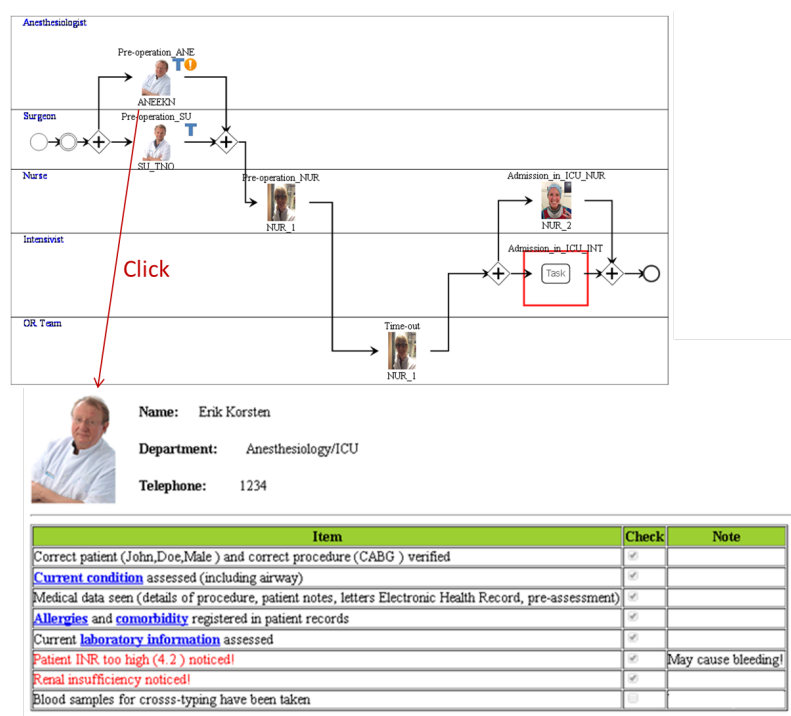

Fig. 4: Reviewing the process and completed checklists.

\section{Current checklists}

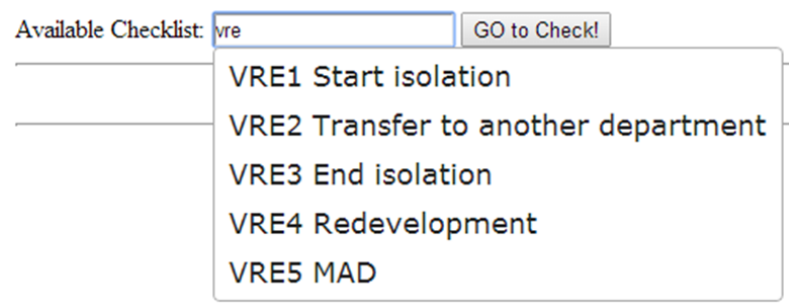

Fig. 5: Selecting an ad-hoc checklist.

in the process, they have a well defined, highly patient-specific checklist to confirm at the right time.

\section{RELATED WORK}

SURPASS Digital, as we described in Section II, made impressive progress in usability and integration with the EMR [13]. However, there are several major differences between SURPASS Digital and Tracebook.

1. SURPASS Digital allows users to pick up a checklist in a list while Tracebook can send a checklist to a specific group of users at the right time. When users try to find a checklist for the patient, in SURPASS Digital, they go to the checklist function in the EMR and select a checklist they want. In Tracebook, a checklist is presented (e.g., by email) to users automatically based on a predefined model.

2. In SURPASS Digital, items in each checklist are unchangeable in the runtime while Tracebook provides personalized items for each patient. Check boxes marked "n/a" are used in SURPASS Digital to deal with the unrelated items. In Tracebook, items are filtered and highlighted by clinical rules according to patient data.

3. SURPASS Digital provides a sequential view of the completed tasks while Tracebook has a comprehensive and straightforward view in BPMN format. In SURPASS Dig- 
ital, an ignored checklist is marked with a red cross, and an incompleted checklist is marked with a red exclamation mark. Tracebook uses a similar mechanism in BPMN format customized with the participants' photos.

In 2012, Avrunin et al. [14] proposed the smart checklists for human-intensive medical systems. Their system can guide process actors in identifying and responding to exceptional or hectic circumstances, help with process deviations and help assure deadlines are met. Checkable items can change dynamically taking into account the history of the process execution, summaries of past execution, and projections of possible future execution of the current process. The smart checklist system focuses on process execution and changes the checklist items dynamically, based on the process context. However, Tracebook dynamically changes the items by the context regarding to patient state.

\section{DISCUSSION}

Besides the safety checklist, clinical pathways and order sets can also be represented in the checklist format [15]. Accordingly, there are computerized clinical pathway systems that can execute pre-scheduled care plans which are localized from clinical pathways [16] and computerized provider order entry (CPOE) systems that are used to give practitioners a package of best practices to a particular group of patients at the point of care [17].

These three types of systems are designed for different purposes. A checklist support system is designed to help the confirmation of critical steps and facilitate the communication among the clinical stakeholders. A computerized clinical pathway system aims to reduce the (undesired) variability in clinical practice, including the standardized order prescription etc. A CPOE system aims to enable fast, convenient ordering and generation of orders that are accurate, complete, and free of errors. As a result, they focus on different functionalities. Particularly, the checklist support system stresses on communication and need to track participants' decisions and provide a global view of the process for each participant.

\section{CONCLUSIONS}

In this paper, we discuss the advantages and limitations of current checklist support systems and present an innovative dynamic checklist support system: Tracebook. Although checklists show their unique power in promoting patient safety by providing users a clear view of critical tasks and helping with the multidisciplinary communication, they are not implemented successfully due to their static supporting systems. We propose a dynamic checklist support system which is processoriented and context-aware to improve this. General features of such a system are discussed. And a prototype of an OR-ICU checklist has demonstrated the feasibility of our approach.

Future work will focus on the deployment, implementation and evaluation of this system. We are planning to implement it in a controlled OR-ICU setting and measure its impact on the checklist acceptance.

\section{ACKNOWLEDGMENT}

The research leading to these results has received funding from the Brain Bridge Project sponsored by Phillips Research.

\section{REFERENCES}

[1] A. B. Haynes, T. G. Weiser, W. R. Berry, S. R. Lipsitz, A.-H. S. Breizat, E. P. Dellinger, T. Herbosa, S. Joseph, P. L. Kibatala, M. C. M. Lapitan, A. F. Merry, K. Moorthy, R. K. Reznick, B. Taylor, and A. a. Gawande, "A surgical safety checklist to reduce morbidity and mortality in a global population." The New England journal of medicine, vol. 360, no. 5, pp. 491-9, Jan. 2009.

[2] E. N. de Vries, H. A. Prins, R. M. P. H. Crolla, A. J. den Outer, G. van Andel, S. H. van Helden, W. S. Schlack, M. A. van Putten, D. J. Gouma, M. G. W. Dijkgraaf, S. M. Smorenburg, and M. A. Boermeester, "Effect of a comprehensive surgical safety system on patient outcomes." The New England journal of medicine, vol. 363, no. 20, pp. 1928-37, Nov. 2010.

[3] A. Borchard, D. L. B. Schwappach, A. Barbir, and P. Bezzola, "A systematic review of the effectiveness, compliance, and critical factors for implementation of safety checklists in surgery." Annals of surgery, vol. 256, no. 6, pp. 925-33, Dec. 2012.

[4] E. N. de Vries, M. W. Hollmann, S. M. Smorenburg, D. J. Gouma, and M. a. Boermeester, "Development and validation of the SURgical PAtient Safety System (SURPASS) checklist." Quality \& safety in health care, vol. 18, no. 2, pp. 121-6, Apr. 2009.

[5] A. Fourcade, J.-L. Blache, C. Grenier, J.-L. Bourgain, and E. Minvielle, "Barriers to staff adoption of a surgical safety checklist." BMJ quality \& safety, vol. 21, no. 3, pp. 191-7, Mar. 2012.

[6] O. Thomassen, G. Brattebø, J.-K. Heltne, E. Sø fteland, and A. Espeland, "Checklists in the operating room: Help or hurdle? A qualitative study on health workers' experiences." BMC health services research, vol. 10, no. 1, p. 342, Jan. 2010.

[7] J. J. Delgado Hurtado, X. Jiménez, M. a. Peñalonzo, C. Villatoro, S. de Izquierdo, and M. Cifuentes, "Acceptance of the WHO Surgical Safety Checklist among surgical personnel in hospitals in Guatemala city." BMC health services research, vol. 12, p. 169, Jan. 2012.

[8] E. A. Sparks, H. Wehbe-Janek, R. L. Johnson, W. R. Smythe, and H. T. Papaconstantinou, "Surgical Safety Checklist Compliance: A Job Done Poorly!" Journal of the American College of Surgeons, no. 0, pp. -, 2013.

[9] S. Tu and J. Campbell, "The SAGE Guideline Model: achievements and overview," Journal of American Medical Informatics Association, vol. 14, no. 5, 2007.

[10] P. A. de Clercq, J. A. Blom, H. H. M. Korsten, and A. Hasman, "Approaches for creating computer-interpretable guidelines that facilitate decision support," Artificial intelligence in medicine, vol. 31, no. 1, pp. 1-27, 2004.

[11] H. van der Sijs, J. Aarts, A. Vulto, and M. Berg, "Overriding of drug safety alerts in computerized physician order entry," Journal of the American Medical Informatics Association, vol. 13, no. 2, pp. 138 147, 2006.

[12] A. F. Arriaga, A. M. Bader, J. M. Wong, S. R. Lipsitz, W. R. Berry, J. E. Ziewacz, D. L. Hepner, D. J. Boorman, C. N. Pozner, D. S. Smink, and A. a. Gawande, "Simulation-based trial of surgical-crisis checklists." The New England journal of medicine, vol. 368, no. 3, pp. 246-53, Jan. 2013.

[13] SURPASS Digital. [Online]. Available: http://www.surpasschecklist.nl/content.jsf?pageId=General\&lang=en

[14] G. S. Avrunin, L. a. Clarke, L. J. Osterweil, J. M. Goldman, and T. Rausch, "Smart checklists for human-intensive medical systems," in IEEE/IFIP International Conference on Dependable Systems and Networks Workshops (DSN 2012). Ieee, Jun. 2012, pp. 1-6.

[15] B. D. Winters, A. P. Gurses, H. Lehmann, J. B. Sexton, C. J. Rampersad, and P. J. Pronovost, "Clinical review: checklists - translating evidence into practice." Critical care (London, England), vol. 13, no. 6, p. 210, Jan. 2009.

[16] W. Li, K. Liu, H. Yang, and C. Yu, "Integrated clinical pathway management for medical quality improvement based on a semiotically inspired systems architecture," European Journal of Information Systems, no. February 2012, pp. 1-18, May 2013.

[17] T. Payne, P. Hoey, P. Nichol, and C. Lovis, "Preparation and use of preconstructed orders, order sets, and order menus in a computerized provider order entry system," Journal of the American Medical Informatics Association, no. 4, pp. 322-330, 2003. 
Working Papers Beta 2009 - 2014

nr. Year Title

4502014 Tracebook: A Dynamic Checklist Support System

$4492014 \underline{\text { Intermodal hinterland network design with multiple }}$ actors

4482014 The Share-a-Ride Problem: People and Parcels Sharing Taxis

4472014 Stochastic inventory models for a single item at a single location

4462014 Optimal and heuristic repairable stocking and expediting in a fluctuating demand environment

4452014 Connecting inventory control and repair shop control: a differentiated control structure for repairable spare parts

4442014 A survey on design and usage of Software Reference Architectures

Extending and Adapting the Architecture Tradeoff 4432014 Analysis Method for the Evaluation of Software $\underline{\text { Reference Architectures }}$

A multimodal network flow problem with product 4422014 Quality preservation, transshipment, and asset $\underline{\text { management }}$

4412013 Integrating passenger and freight transportation: Model formulation and insights

4402013 The Price of Payment Delay

4392013 On Characterization of the Core of Lane Covering Games via Dual Solutions

4382013 Destocking, the Bullwhip Effect, and the Credit Crisis: Empirical Modeling of Supply Chain
Author(s)

Shan Nan, Pieter Van Gorp, Hendrikus H.M. Korsten, Richard Vdovjak, Uzay Kaymak

Yann Bouchery, Jan Fransoo

Baoxiang Li, Dmitry Krushinsky, Hajo A. Reijers, Tom Van Woensel

K.H. van Donselaar, R.A.C.M.

Broekmeulen

Joachim Arts, Rob Basten, Geert-Jan van Houtum

M.A. Driessen, W.D. Rustenburg, G.J. van Houtum, V.C.S. Wiers

Samuil Angelov, Jos Trienekens, Rob Kusters

Samuil Angelov, Jos J.M. Trienekens, Paul Grefen

Maryam SteadieSeifi, Nico Dellaert, Tom Van Woensel

Veaceslav Ghilas, Emrah Demir, Tom Van Woensel

K. van der Vliet, M.J. Reindorp,

J.C. Fransoo

Behzad Hezarkhani, Marco Slikker, Tom van Woensel

Maximiliano Udenio, Jan C. Fransoo, Robert Peels 
4372013 Methodological support for business process Redesign in healthcare: a systematic literature review

4362013 Dynamics and equilibria under incremental Horizontal differentiation on the Salop circle

4352013 Analyzing Conformance to Clinical Protocols Involving Advanced Synchronizations

4342013 Models for Ambulance Planning on the Strategic and the Tactical Level

4332013 Mode Allocation and Scheduling of Inland Container Transportation: A Case-Study in the Netherlands

Socially responsible transportation and lot sizing:

4322013 Insights from multiobjective optimization

4312013 Inventory routing for dynamic waste collection

4302013 Simulation and Logistics Optimization of an $\underline{\text { Integrated Emergency Post }}$

4292013 Last Time Buy and Repair Decisions for Spare Parts

4282013

A Review of Recent Research on Green Road Freight Transportation

Typology of Repair Shops for Maintenance

4272013 Spare Parts
Rob J.B. Vanwersch, Khurram Shahzad, Irene Vanderfeesten, Kris Vanhaecht, Paul Grefen, Liliane Pintelon, Jan Mendling, Geofridus G. Van Merode, Hajo A. Reijers

B. Vermeulen, J.A. La Poutré, A.G. de Kok

Hui Yan, Pieter Van Gorp, Uzay Kaymak, Xudong Lu, Richard Vdovjak, Hendriks H.M. Korsten, Huilong Duan

J. Theresia van Essen, Johann L. Hurink, Stefan Nickel, Melanie Reuter

Stefano Fazi, Tom Van Woensel, Jan C. Fransoo

Yann Bouchery, Asma Ghaffari, Zied Jemai, Jan Fransoo

Martijn Mes, Marco Schutten, Arturo Pérez Rivera

N.J. Borgman, M.R.K. Mes, I.M.H. Vliegen, E.W. Hans

S. Behfard, M.C. van der Heijden, A. Al Hanbali, W.H.M. Zijm

Emrah Demir, Tolga Bektas, Gilbert Laporte

M.A. Driessen, V.C.S. Wiers, G.J. van Houtum, W.D. Rustenburg 
A value network development model and

4262013 Implications for innovation and production network B. Vermeulen, A.G. de Kok $\underline{\text { management }}$

Single Vehicle Routing with Stochastic Demands: C. Zhang, N.P. Dellaert, L. Zhao, 4252013 Approximate Dynamic Programming T. Van Woensel, D. Sever

Influence of Spillback Effect on Dynamic Shortest 4242013 Path Problems with Travel-Time-Dependent Network Disruptions

Derya Sever, Nico Dellaert, Tom Van Woensel, Ton de Kok

4232013 Dynamic Shortest Path Problem with Travel-TimeDependent Stochastic Disruptions: Hybrid Approximate Dynamic Programming Algorithms with a Clustering Approach

System-oriented inventory models for spare 4222013 parts

Lost Sales Inventory Models with Batch Ordering 4212013 And Handling Costs

T. Van Woensel, N. Erkip, A. Curseu, J.C. Fransoo

4202013 Response speed and the bullwhip

Maximiliano Udenio, Jan C. Fransoo, Eleni Vatamidou, Nico Dellaert

4192013 Anticipatory Routing of Police Helicopters

Rick van Urk, Martijn R.K. Mes, Erwin W. Hans

Kasper van der Vliet, Matthew J.

4182013 Supply Chain Finance: research challenges ahead

Improving the Performance of Sorter Systems

4172013 By Scheduling Inbound Containers Reindorp, Jan C. Fransoo

S.W.A. Haneyah, J.M.J. Schutten, K. Fikse

Regional logistics land allocation policies:

4162013 Stimulating spatial concentration of logistics $\underline{\text { firms }}$

Frank P. van den Heuvel, Peter W. de Langen, Karel $\mathrm{H}$. van Donselaar, Jan C. Fransoo

The development of measures of process 4152013 harmonization Heidi L. Romero, Remco M. Dijkman, Paul W.P.J. Grefen, Arjan van Weele 
BASE/X. Business Agility through Cross-

4142013 Organizational Service Engineering

The Time-Dependent Vehicle Routing Problem 4132013 with Soft Time Windows and Stochastic Travel Times

4122013 Clearing the Sky - Understanding SLA Elements in Cloud Computing

4112013 Approximations for the waiting time distribution In an $M / G / C$ priority queue

4102013 To co-locate or not? Location decisions and logistics concentration areas

4092013 The Time-Dependent Pollution-Routing Problem

$4082013 \frac{\text { Scheduling the scheduling task: A time }}{\text { Management perspective on scheduling }}$

4072013 Clustering Clinical Departments for Wards to Achieve a Prespecified Blocking Probability

$4062013 \frac{\text { MyPHRMachines: Personal Health Desktops }}{\text { in }}$ 4052013 Maximising the Value of Supply Chain Finance $4042013 \frac{\text { Reaching } 50 \text { million nanostores: retail }}{\text { distribution in emerging megacities }}$ $4032013 \frac{\text { A Vehicle Routing Problem with Flexible Time }}{\text { Windows }}$
Paul Grefen, Egon Lüftenegger, Eric van der Linden, Caren Weisleder

Duygu Tas, Nico Dellaert, Tom van Woensel, Ton de Kok

Marco Comuzzi, Guus Jacobs, Paul Grefen
A. Al Hanbali, E.M. Alvarez, M.C. van der van der Heijden

Frank P. van den Heuvel, Karel H. van Donselaar, Rob A.C.M. Broekmeulen, Jan C. Fransoo, Peter W. de Langen

Anna Franceschetti, Dorothée Honhon, Tom van Woensel, Tolga Bektas, GilbertLaporte.

J.A. Larco, V. Wiers, J. Fransoo

J. Theresia van Essen, Mark van Houdenhoven, Johann L. Hurink

Pieter Van Gorp, Marco Comuzzi

Kasper van der Vliet, Matthew J. Reindorp, Jan C. Fransoo

Edgar E. Blanco, Jan C. Fransoo

Duygu Tas, Ola Jabali, Tom van Woensel 
4022012 The Service Dominant Business Model: A Service Focused Conceptualization

4012012 Relationship between freight accessibility and Logistics employment in US counties

4002012 A Condition-Based Maintenance Policy for MultiComponent Systems with a High Maintenance Setup Cost

3992012 A flexible iterative improvement heuristic to Support creation of feasible shift rosters in Self-rostering

Scheduled Service Network Design with 3982012 Synchronization and Transshipment Constraints For Intermodal Container Transportation Networks

3972012 Destocking, the bullwhip effect, and the credit Crisis: empirical modeling of supply chain Dynamics

3962012 Vehicle routing with restricted loading capacities

3952012 Service differentiation through selective $\underline{\text { lateral transshipments }}$

3942012 A Generalized Simulation Model of an Integrated Emergency Post

3932012 Business Process Technology and the Cloud: Defining a Business Process Cloud Platform

3922012 Vehicle Routing with Soft Time Windows and Stochastic Travel Times: A Column Generation
Egon Lüftenegger, Marco Comuzzi, Paul Grefen, Caren Weisleder

Frank P. van den Heuvel, Liliana Rivera,Karel H. van Donselaar, Ad de Jong, Yossi Sheffi, Peter W. de Langen, Jan C.Fransoo

Qiushi Zhu, Hao Peng, Geert-Jan van Houtum

E. van der Veen, J.L. Hurink, J.M.J. Schutten, S.T. Uijland

K. Sharypova, T.G. Crainic, T. van Woensel, J.C. Fransoo

Maximiliano Udenio, Jan C. Fransoo, Robert Peels

J. Gromicho, J.J. van Hoorn, A.L. Kok J.M.J. Schutten

E.M. Alvarez, M.C. van der Heijden, I.M.H. Vliegen, W.H.M. Zijm

Martijn Mes, Manon Bruens

Vasil Stoitsev, Paul Grefen

D. Tas, M. Gendreau, N. Dellaert, T. van Woensel, A.G. de Kok 


\section{And Branch-and-Price Solution Approach}

$3912012 \underline{\text { Improve OR-Schedule to Reduce Number of }}$ $\underline{\text { Required Beds }}$

3902012 How does development lead time affect performance over the ramp-up lifecycle?

\section{Evidence from the consumer electronics}

3892012 industry

The Impact of Product Complexity on Ramp3882012 Up Performance

Co-location synergies: specialized versus diverse 3872012 logistics concentration areas

Proximity matters: Synergies through co-location 3862012 of logistics establishments

Spatial concentration and location dynamics in 3852012 logistics:the case of a Dutch province

$3842012 \frac{\text { FNet: An Index for Advanced Business Process }}{\text { Querying }}$ 3832012 Defining Various Pathway Terms

3822012 The Service Dominant Strategy Canvas: Defining and Visualizing a Service Dominant Strategy through the Traditional Strategic Lens

$3812012 \frac{\text { A Stochastic Variable Size Bin Packing Problem }}{\text { With }}$ With Time Constraints
J.T. v. Essen, J.M. Bosch, E.W. Hans, M. v. Houdenhoven, J.L. Hurink

Andres Pufall, Jan C. Fransoo, Ad de Jong

Andreas Pufall, Jan C. Fransoo, Ad de Jong, Ton de Kok

Frank P.v.d. Heuvel, Peter W.de Langen,

Karel H. v. Donselaar, Jan C. Fransoo

Frank P.v.d. Heuvel, Peter W.de Langen,

Karel H. v.Donselaar, Jan C. Fransoo

Frank P. v.d. Heuvel, Peter W.de Langen,

Karel H.v. Donselaar, Jan C. Fransoo

Zhiqiang Yan, Remco Dijkman, Paul Grefen

W.R. Dalinghaus, P.M.E. Van Gorp

Egon Lüftenegger, Paul Grefen, Caren Weisleder

Stefano Fazi, Tom van Woensel, Jan C. Fransoo

K. Sharypova, T. van Woensel, J.C. Fransoo 
3802012 Coordination and Analysis of Barge Container Hinterland Networks

3792012 Proximity matters: Synergies through co-location of logistics establishments

3782012 A literature review in process harmonization: a conceptual framework $3772012 \frac{\text { A Generic Material Flow Control Model for }}{\underline{\text { Two Different Industries }}}$

$3752012 \underline{\text { Improving the performance of sorter systems by }}$

$3752012 \underline{\text { Improving the performance of sorter systems by }}$

Strategies for dynamic appointment making by

3742012 container terminals

MyPHRMachines: Lifelong Personal Health 3732012 Records in the Cloud

$3722012 \frac{\text { Service differentiation in spare parts supply }}{\text { through dedicated stocks }}$

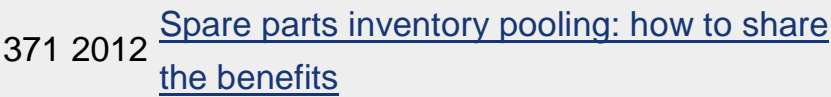

3702012 Condition based spare parts supply $3692011 \frac{\text { Using Simulation to Assess the Opportunities of }}{\text { Dynamic Waste Collection }}$

Aggregate overhaul and supply chain planning for 3682011 rotables
Frank P. van den Heuvel, Peter W. de Langen, Karel $\mathrm{H}$. van Donselaar, Jan C.

Fransoo

Heidi Romero, Remco Dijkman, Paul Grefen, Arjan van Weele

S.W.A. Haneya, J.M.J. Schutten, P.C. Schuur, W.H.M. Zijm

H.G.H. Tiemessen, M. Fleischmann, G.J. van Houtum, J.A.E.E. van Nunen, E. Pratsini

Albert Douma, Martijn Mes

Pieter van Gorp, Marco Comuzzi

E.M. Alvarez, M.C. van der Heijden, W.H.M. Zijm

Frank Karsten, Rob Basten

X.Lin, R.J.I. Basten, A.A. Kranenburg, G.J. van Houtum

Martijn Mes

J. Arts, S.D. Flapper, K. Vernooij

J.T. van Essen, J.L. Hurink, W. Hartholt,

B.J. van den Akker 
3672011 Operating Room Rescheduling

3662011 Switching Transport Modes to Meet Voluntary Carbon Emission Targets

3652011 On two-echelon inventory systems with Poisson demand and lost sales

3642011

Minimizing the Waiting Time for Emergency

Surgery

Vehicle Routing Problem with Stochastic Travel

3632011 Times Including Soft Time Windows and Service $\underline{\text { Costs }}$

3622011 A New Approximate Evaluation Method for TwoEchelon Inventory Systems with Emergency Shipments

3612011 Approximating Multi-Objective Time-Dependent Optimization Problems

3602011 Branch and Cut and Price for the Time Dependent Vehicle Routing Problem with Time Window

3592011 Analysis of an Assemble-to-Order System with Different Review Periods

$3582011 \frac{\text { Interval Availability Analysis of a Two-Echelon, }}{\text { Multi-Item System }}$

Carbon-Optimal and Carbon-Neutral Supply

$3572011 \underline{\text { Chains }}$

Generic Planning and Control of Automated

3562011 Material Handling Systems: Practical Requirements Versus Existing Theory

3552011 Last time buy decisions for products sold under warranty

3542011 Spatial concentration and location dynamics in logistics: the case of a Dutch provence
Kristel M.R. Hoen, Tarkan Tan, Jan C Fransoo, Geert-Jan van Houtum

Elisa Alvarez, Matthieu van der Heijden

J.T. van Essen, E.W. Hans, J.L. Hurink, A. Oversberg

Duygu Tas, Nico Dellaert, Tom van Woensel, Ton de Kok

Erhun Özkan, Geert-Jan van Houtum, Yasemin Serin

Said Dabia, El-Ghazali Talbi, Tom Van Woensel, Ton de Kok

Said Dabia, Stefan Röpke, Tom Van Woensel, Ton de Kok

A.G. Karaarslan, G.P. Kiesmüller, A.G. de Kok

Ahmad Al Hanbali, Matthieu van der Heijden

Felipe Caro, Charles J. Corbett, Tarkan Tan, Rob Zuidwijk

Sameh Haneyah, Henk Zijm, Marco Schutten, Peter Schuur

M. van der Heijden, B. Iskandar

Frank P. van den Heuvel, Peter W. de Langen, Karel $\mathrm{H}$. van Donselaar, Jan C. Fransoo

Frank P. van den Heuvel, Peter W. de Langen, Karel $\mathrm{H}$. van Donselaar, Jan C. Fransoo 
3522011 BOMN 2.0 Execution Semantics Formalized as Graph Rewrite Rules: extended version

3512011 Resource pooling and cost allocation among independent service providers

3502011

A Framework for Business Innovation Directions

3492011 The Road to a Business Process Architecture: An Overview of Approaches and their Use

Effect of carbon emission regulations on transport 3482011 mode selection under stochastic demand

An improved MIP-based combinatorial approach 3472011 for a multi-skill workforce scheduling problem

An approximate approach for the joint problem of 3462011 level of repair analysis and spare parts stocking

$3452011 \frac{\text { Joint optimization of level of repair analysis and }}{\text { spare parts stocks }}$ Inventory control with manufacturing lead time 3442011 flexibility

Analysis of resource pooling games via a new 3432011 extenstion of the Erlang loss function

3422010 Vehicle refueling with limited resources

3412010 Optimal Inventory Policies with Non-stationary Supply Disruptions and Advance Supply Information

Redundancy Optimization for Critical Components 3392010 in High-Availability Capital Goods
Frank Karsten, Marco Slikker, GeertJan van Houtum

E. Lüftenegger, S. Angelov, P. Grefen

Remco Dijkman, Irene Vanderfeesten, Hajo A. Reijers

K.M.R. Hoen, T. Tan, J.C. Fransoo

G.J. van Houtum

Murat Firat, Cor Hurkens

R.J.I. Basten, M.C. van der Heijden,

J.M.J. Schutten

R.J.I. Basten, M.C. van der Heijden, J.M.J. Schutten

Ton G. de Kok

Frank Karsten, Marco Slikker, GeertJan van Houtum

Murat Firat, C.A.J. Hurkens, Gerhard J. Woeginger

Bilge Atasoy, Refik Güllü, TarkanTan

Kurtulus Baris Öner, Alan Scheller-Wolf Geert-Jan van Houtum

Joachim Arts, Gudrun Kiesmüller 
3352010 Analysis of the dial-a-ride problem of Hunsaker and Savelsbergh

Murat Firat, Cor Hurkens

3342010 Attaining stability in multi-skill workforce scheduling

A.J.M.M. Weijters, J.T.S. Ribeiro

3332010 Flexible Heuristics Miner (FHM)

P.T. Vanberkel, R.J. Boucherie, E.W. Hans, J.L. Hurink, W.A.M. van Lent, W.H. van Harten

3322010 An exact approach for relating recovering surgical patient workload to the master surgical schedule

Efficiency evaluation for pooling resources in

3312010 health care

The Effect of Workload Constraints in

Peter T. Vanberkel, Richard J.

Boucherie, Erwin W. Hans, Johann L. Hurink, Nelly Litvak

M.M. Jansen, A.G. de Kok, I.J.B.F. Adan

3302010 Mathematical Programming Models for Production Planning

Christian Howard, Ingrid Reijnen, Johan Marklund, Tarkan Tan

$3292010 \frac{\text { Using pipeline information in a multi-echelon spare }}{\text { parts inventory system }}$

Reducing costs of repairable spare parts supply 3282010 systems via dynamic scheduling

Identification of Employment Concentration and 3272010 Specialization Areas: Theory and Application

H.G.H. Tiemessen, G.J. van Houtum

F.P. van den Heuvel, P.W. de Langen, K.H. van Donselaar, J.C. Fransoo

Murat Firat, Cor Hurkens

A combinatorial approach to multi-skill workforce 3262010 scheduling

Murat Firat, Cor Hurkens, Alexandre Laugier

3252010 Stability in multi-skill workforce scheduling

M.A. Driessen, J.J. Arts, G.J. v.

Houtum, W.D. Rustenburg, B. Huisman

$3242010 \frac{\text { Maintenance spare parts planning and control: A }}{\underline{\text { framework for control and agenda for future }}}$

R.J.I. Basten, G.J. van Houtum

Near-optimal heuristics to set base stock levels in 3232010 a two-echelon distribution network 
M.C. van der Heijden, E.M. Alvarez, J.M.J. Schutten

3222010 Inventory reduction in spare part networks by selective throughput time reduction

E.M. Alvarez, M.C. van der Heijden, W.H. Zijm

3212010 The selective use of emergency shipments for service-contract differentiation

B. Walrave, K. v. Oorschot, A.G.L. Romme

3202010 Heuristics for Multi-Item Two-Echelon Spare Parts Inventory Control Problem with Batch Ordering in the Central Warehouse

Preventing or escaping the suppression

3192010 mechanism: intervention conditions

Nico Dellaert, Jully Jeunet.

Hospital admission planning to optimize major 3182010 resources utilization under uncertainty

3172010 Minimal Protocol Adaptors for Interacting Services

R. Seguel, R. Eshuis, P. Grefen.

Tom Van Woensel, Marshall L. Fisher, Jan C. Fransoo.

Lydie P.M. Smets, Geert-Jan van Houtum, Fred Langerak.

Pieter van Gorp, Rik Eshuis.

Bob Walrave, Kim E. van Oorschot, A. Georges L. Romme

Transforming Process Models: executable rewrite 3142010 rules versus a formalized Java program

Getting trapped in the suppression of exploration: 313 A simulation model

A Dynamic Programming Approach to MultiObjective Time-Dependent Capacitated Single Vehicle Routing Problems with Time Windows

Tales of a So(u)rcerer: Optimal Sourcing Decisions 3122010 Under Alternative Capacitated Suppliers and General Cost Structures

In-store replenishment procedures for perishable

3112010 inventory in a retail environment with handling costs and storage constraints

3102010 The state of the art of innovation-driven business models in the financial services industry

S. Dabia, T. van Woensel, A.G. de Kok Osman Alp, Tarkan Tan

R.A.C.M. Broekmeulen, C.H.M. Bakx

E. Lüftenegger, S. Angelov, E. van der Linden, P. Grefen

3092010 Design of Complex Architectures Using a Three Dimension Approach: the CrossWork Case

R. Seguel, P. Grefen, R. Eshuis

3082010 Effect of carbon emission regulations on transport mode selection in supply chains

K.M.R. Hoen, T. Tan, J.C. Fransoo, G.J. van Houtum 
$3072010 \frac{\text { Interaction between intelligent agent strategies for }}{\text { real-time transportation planning }}$

3062010 Internal Slackening Scoring Methods

$3052010 \frac{\text { Vehicle Routing with Traffic Congestion and }}{\text { Drivers' Driving and Working Rules }}$

3042010 Practical extensions to the level of repair analysis

Ocean Container Transport: An Underestimated

3032010 and Critical Link in Global Supply Chain Performance

3022010 Capacity reservation and utilization for a manufacturer with uncertain capacity and demand

3002009 Spare parts inventory pooling games

2992009 Capacity flexibility allocation in an outsourced supply chain with reservation

2982010 An optimal approach for the joint problem of level of repair analysis and spare parts stocking

Responding to the Lehman Wave: Sales

2972009 Forecasting and Supply Management during the Credit Crisis $2962009 \frac{\text { An exact approach for relating recovering surgical }}{\text { patient workload to the master surgical schedule }}$

An iterative method for the simultaneous

2952009 optimization of repair decisions and spare parts stocks

2942009 Fujaba hits the Wall(-e)

2932009 Implementation of a Healthcare Process in Four Different Workflow Systems

2922009 Business Process Model Repositories - Framework Zhiqiang Yan, Remco Dijkman, Paul and Survey

2912009 Efficient Optimization of the Dual-Index Policy Using Markov Chains $2902009 \frac{\text { Hierarchical Knowledge-Gradient for Sequential }}{\text { Sampling }}$

Analyzing combined vehicle routing and break

2892009 scheduling from a distributed decision making perspective

2882009 Anticipation of lead time performance in Supply Chain Operations Planning

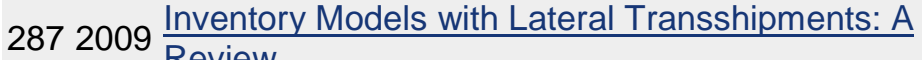
$\underline{\text { Review }}$
Martijn Mes, Matthieu van der Heijden, Peter Schuur

Marco Slikker, Peter Borm, René van den Brink

A.L. Kok, E.W. Hans, J.M.J. Schutten, W.H.M. Zijm

R.J.I. Basten, M.C. van der Heijden, J.M.J. Schutten

Jan C. Fransoo, Chung-Yee Lee

Y. Boulaksil; J.C. Fransoo; T. Tan

F.J.P. Karsten; M. Slikker; G.J. van Houtum

Y. Boulaksil, M. Grunow, J.C. Fransoo

R.J.I. Basten, M.C. van der Heijden, J.M.J. Schutten

Robert Peels, Maximiliano Udenio, Jan C. Fransoo, Marcel Wolfs, Tom Hendrikx

Peter T. Vanberkel, Richard J.

Boucherie, Erwin W. Hans, Johann L. Hurink, Wineke A.M. van Lent, Wim H. van Harten

R.J.I. Basten, M.C. van der Heijden, J.M.J. Schutten

Pieter van Gorp, Ruben Jubeh, Bernhard Grusie, Anne Keller

R.S. Mans, W.M.P. van der Aalst, N.C. Russell, P.J.M. Bakker

Grefen

Joachim Arts, Marcel van Vuuren, Gudrun Kiesmuller

Martijn R.K. Mes; Warren B. Powell; Peter I. Frazier

C.M. Meyer; A.L. Kok; H. Kopfer; J.M.J. Schutten

Michiel Jansen; Ton G. de Kok; Jan C. Fransoo

Colin Paterson; Gudrun Kiesmuller; Ruud Teunter; Kevin Glazebrook 
2862009 Efficiency evaluation for pooling resources in

$2852009 \frac{\text { A Survey of Health Care Models that Encompass }}{\text { Multiple }}$ Multiple Departments

$2842009 \frac{\text { Supporting Process Control in Business }}{\text { Collaborations }}$

2832009 Inventory Control with Partial Batch Ordering

2822009 Translating Safe Petri Nets to Statecharts in a Structure-Preserving Way

2812009 The link between product data model and process $\underline{\text { model }}$

$2802009 \frac{\text { Inventory planning for spare parts networks with }}{\text { detivy }}$ delivery time requirements

2792009 Co-Evolution of Demand and Supply under Competition

Toward Meso-level Product-Market Network

2782010 Indices for Strategic Product Selection and

(Re)Design Guidelines over the Product Life-Cycle

An Efficient Method to Construct Minimal Protocol 2772009 Adaptors

2762009 Coordinating Supply Chains: a Bilevel Programming Approach

$2752009 \frac{\text { Inventory redistribution for fashion products under }}{\text { demand parameter update }}$

2742009 Comparing Markov chains: Combining aggregation and precedence relations applied to sets of states 2732009 Separate tools or tool kits: an exploratory study of

An Exact Solution Procedure for Multi-Item Two-

2722009 Echelon Spare Parts Inventory Control Problem with Batch Ordering $2712009 \frac{\text { Distributed Decision Making in Combined Vehicle }}{\text { Routing and Break Scheduling }}$

Dynamic Programming Algorithm for the Vehicle

2702009 Routing Problem with Time Windows and EC Social Legislation

2692009 Similarity of Business Process Models: Metics and Evaluation $2672009 \frac{\text { Vehicle routing under time-dependent travel times: }}{\text { the impact of congestion avoidance }}$

2662009 Restricted dynamic programming: a flexible framework for solving realistic VRPS
P.T. Vanberkel; R.J. Boucherie; E.W. Hans; J.L. Hurink; N. Litvak

P.T. Vanberkel; R.J. Boucherie; E.W. Hans; J.L. Hurink; N. Litvak

S. Angelov; K. Vidyasankar; J. Vonk; P. Grefen

O. Alp; W.T. Huh; T. Tan

R. Eshuis

J.J.C.L. Vogelaar; H.A. Reijers

I.C. Reijnen; T. Tan; G.J. van Houtum

B. Vermeulen; A.G. de Kok

B. Vermeulen, A.G. de Kok

R. Seguel, R. Eshuis, P. Grefen

Ton G. de Kok, Gabriella Muratore

G.P. Kiesmuller, S. Minner

A. Busic, I.M.H. Vliegen, A. SchellerWolf

I.M.H. Vliegen, P.A.M. Kleingeld, G.J. van Houtum

Engin Topan, Z. Pelin Bayindir, Tarkan Tan

C.M. Meyer, H. Kopfer, A.L. Kok, M. Schutten

A.L. Kok, C.M. Meyer, H. Kopfer, J.M.J. Schutten

Remco Dijkman, Marlon Dumas,

Boudewijn van Dongen, Reina Kaarik, Jan Mendling

A.L. Kok, E.W. Hans, J.M.J. Schutten

J. Gromicho; J.J. van Hoorn; A.L. Kok; J.M.J. Schutten; 
Working Papers published before 2009 see: http://beta.ieis.tue.nl 